Dykha O.V. Babak O.P. Dytynyuk V.O.

Khmelnytskyi National University, Khmelnytskyi, Ukraine

E-mail: tribosenator@gmail.com

UDC 621.891

DOI:10.31891/2079-1372-2019-91-1-59-66

\title{
DIRECT WEAR-CONTACT TASK FOR RADIAL SLIDING BEARING
}

The paper presents an approximate solution of the wear-contact problem for a cylindrical sliding bearing. The law of wear is adopted in a dimensionless form, depending on the determining factors: contact pressure and sliding speed. The law of wear also includes: the coefficient of friction, the modulus of elasticity of the material of the bearing, the gap in the bearing and the thermal diffusivity of the material of the bearing. For the calculation, an approximate relationship was used for maximum contact pressures in the bearing. To simplify the geometric dependence of normal wear on the contact angle, the decomposition of trigonometric functions into a power series was used.

Key words: sliding bearing, wear, contact pressure, speed, power series.

\section{Introduction}

The creation of design models of wear resistance of modern friction units of machines is complicated by the many-sided nature of the interrelationships of various factors during wear. As a rule, these connections are nonlinear. That in turn leads to mathematical difficulties in solving wear contact problems. Often the solution is possible only in numerical form.

In many energy and transport vehicles (internal combustion engines, turbines, cars, etc.), plain bearings are one of the main components that determine the durability and reliability of the machine as a whole. Analysis of the current state of methods for calculating and designing sliding bearings shows that they are lagging behind the general level and requirements. Therefore, for engineering applications, it is advisable to use approximate approaches. In this direction there is a small number of studies presented below.

In paper [1] using a generalized cumulative wear model, the tribocontact problem has been solved for a sliding bearing, the shaft of which has small contour lobing with various forms. The effect of lobing on the bearing life has been investigated at the complete single-area and mixed-area contact. It has been found that the ovality and trilobing of the shaft promote a rise in the service life. Features of this effect are presented graphically.

The evolution of contact pressure is analyzed in paper [2] during the wear of a thrust sliding bearing following the law of nonlinear wear. The coating's deformation properties are described using the nonlinear Winkler model. It is demonstrated that steady wear can exist with a definite contact pressure distribution.

In article [3] the problem of simultaneous wear of an elastic cylinder and a cylindrical notch surface in an elastic space is discussed (in the planar formulation). The contact problem formulation omits the limitation of the contact area. The contact is solved in steps; the linear wear and contact parameters of the shaft and bush are solved at each step in time. The Multopp-Kalandia method is applied to the solution of the contact problem. The constructed model is used to investigate the evolution of contact pressure and form changes of the shaft and bush in the process of wear.

The parameter of the wear law of bronze coupled with steel under dry friction is identified by comparing the results of mathematical modeling with experimental data [4]. The wear tests were carried out according to the steel-ball-flat-bronze sample scheme under relative reciprocal sliding of the tested samples. The modeling of the wear of the sample was based on asymptotic behavior of the solution of the corresponding wear-contact problem. The effectiveness of using this asymptotic behavior to identify the wear law based on the tribological test results has been demonstrated.

Based on pin-on-disk friction and wear testing, the parameters of the wear rate as a function of sliding velocity and pressure with account for their distribution over the contact spot are computed in paper [5]. The parameters are compared to those obtained assuming a uniform distribution of velocities and pressures. It is assumed in the work that the contact spot does not vary, the disk does not wear out, and the study is carried out under steady-state wear conditions.

The kinetics of sample wear on a four-ball friction-testing machine using various lubricants is analyzed in [6]. It is shown that the growth of the contact-patch area on the balls obeys the kinetic second-order equation, which, within the limits, corresponds to catastrophic wear. The linear wear rates and the strain level of the ball material in different lubricating media are estimated. 
The article [7] employs an adaptive wear modeling method to study the wear progress in radial sliding bearings contacting with a rotary shaft. Mixed Lagrangian-Eulerian formulation has been used to simulate the contact condition between the bearing and the shaft, and the local wear evolution is modeled using the Archard equation. In the developed wear processor algorithm, not only remeshing is performed on the contact elements, but also is executed for their proximity elements. In this way the wear simulation becomes independent of the size of the contact elements. Validation was done for a laminated polymeric composite bearing. The composite has been modeled as a linear orthotropic material. The wear coefficients were obtained from flat-on-flat experiments and were applied as pressure and velocity dependent parameters in the wear processor. Finally, the effect of the clearance on the wear of the radial bearings has been studied numerically. The simulations also demonstrate how the contact pressure evolves during the wear process, and how the clearance influences this evolution.

In our works [8 - 10], we have proposed experimental design approaches for solving wear-contact problems for sliding bearings. On the basis of direct and inverse wear-contact tasks, algorithms are presented for calculating bearing wear and identifying the parameters of their wear laws. At the same time there are difficulties in the engineering implementation of the solutions obtained.

Therefore, for practical use, algorithms for calculating the service life of bearings using simple algebraic dependencies and formulas are necessary.

\section{Direct wear-contact task for radial sliding bearing}

Under the wear contact task is the task of determining the magnitude of the maximum linear wear in a bearing, depending on the friction path. The structural data, load, kinematic parameters of the bearing, as well as the wear law with the parameters of wear resistance are taken as the initial data.

Cylindrical sliding bearings represent the internal contact of two cylinders of similar radii with a radial clearance $\Delta$ (Fig. 1). The shaft of radius $R_{1}$ of the bearing is loaded with force $Q$ and performs rotational movement with sliding speed $V$ along sleeve 2 with radius $R$. In the process of force interaction of the shaft and bearing sleeve, a contact pressure $\sigma$ appears along the contact arc $2 \varphi_{0}$ in the place of contact of two cylinders.

It is assumed that the wear resistance of the shaft is much greater than the wear resistance of the sleeve (straight friction pair). During operation, an arc zone is formed on the inner surface of the sleeve, with a maximum value at the center of contact $u_{W}$.

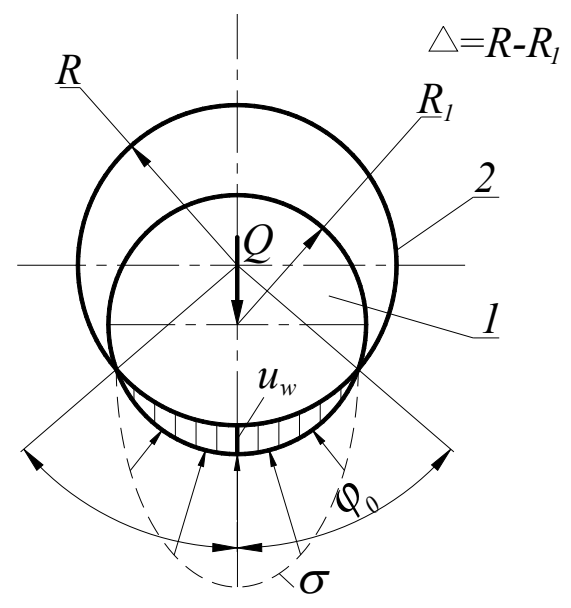

Fig. 1 - The design scheme of the cylindrical sliding bearing

For an analytical solution of the problem of calculating the wear of a sliding bearing, the mathematical form of the law of wear is taken as the initial value. The representation of such laws as a dependence of the wear rate on the determining parameters of the process (contact pressure, sliding speed, temperature, etc.) is widely used. In our case, the law (model) of wear is adopted in the form of a dimensionless complex of determining factors: For an analytical solution of the problem of calculating wear of a sliding bearing, the mathematical form of the law of wear is taken as the initial value. The representation of such laws as a dependence of the wear rate on the determining parameters of the process (contact pressure, sliding speed, temperature, etc.) is widely used. In our case, the law (model) of wear is adopted in the form of a dimensionless complex of determining factors: 


$$
\frac{d u_{W}}{d S}=K_{W} f\left(\frac{\sigma\left(\varphi_{0}\right)}{E}\right)^{m}\left(\frac{V \Delta}{a}\right)^{n},
$$

where $u_{W}$ is the bearing wear;

$S$ is the friction path;

$f$ is the coefficient of friction in a pair of shaft-sleeve;

$\sigma$ is the normal contact pressure;

$E$ is the modulus of elasticity of the sleeve material;

$V$ is the sliding speed;

$R$ is the radius of the bearing (sleeve);

$a$ is the coefficient of thermal diffusivity of the bearing material;

$K_{W}, m, n$ are the wear resistance parameters;

$\varphi_{0}$ is the half angle of the contact shaft and sleeve

To calculate the maximum wear we use the values of the maximum contact pressure. With a known contact angle, the maximum contact pressures can be determined by the formula:

$$
\sigma_{0}=\frac{Q}{b R_{1}} \frac{1-\cos \varphi_{0}}{\varphi_{0}-\sin \varphi_{0} \cos \varphi_{0}} .
$$

We use the approximate decomposition of trigonometric functions in the series:

$$
\sigma_{0}=\frac{Q}{b R_{1}} \frac{1-1+\frac{1}{2} \varphi_{0}{ }^{2}}{\varphi_{0}-\left(\varphi_{0}-\frac{1}{6} \varphi_{0}{ }^{3}\right)\left(1-\frac{1}{2} \varphi_{0}{ }^{2}\right)} \cong \frac{3 Q}{4 b R_{1} \varphi_{0}},
$$

where $Q$ is the bearing load;

$b$ is the width of the contact shaft and sleeve.

The relationship between maximum wear $u_{W}$ and the contact angle is determined from the geometry of the internal contact of two cylinders with a radial initial clearance $\Delta$ according to:

$$
u_{W}=\Delta\left(\frac{1}{\cos \varphi_{0}}-1\right)
$$

Where the contact angle is determined:

$$
\varphi_{0}=\arccos \left(\frac{\Delta}{u_{W}+\Delta}\right)
$$

More convenient approximate algebraic formulas for determining the contact angle are possible. Formula (5) by decomposition of the cosine in a power series and discarding the members of the highest order of smallness is reduced to the form:

$$
\varphi_{0}=\left(\frac{2 u_{W}}{u_{W}+\Delta}\right)^{\frac{1}{2}} 2=\left(\frac{2}{1+\Delta / u_{W}}\right)^{\frac{1}{2}}=\left(\frac{2\left(u_{W} / \Delta\right)}{u_{W} / \Delta+1}\right)^{\frac{1}{2}}
$$

From (5) in the decomposition of the cosine: 


$$
\begin{gathered}
\cos \varphi_{0}=1-\frac{1}{2} \varphi_{0}^{2}=\frac{\Delta}{u_{W}+\Delta} ; \\
\varphi_{0}=\left(\frac{2 u_{W}}{u_{W}+\Delta}\right)^{\frac{1}{2}}
\end{gathered}
$$

Expression (5) can be inverted and presented as a secant:

$$
\sec \varphi_{0}=\frac{u_{W}+\Delta}{\Delta}=\frac{u_{W}}{\Delta}+1
$$

or

$$
\begin{aligned}
\sec \varphi_{0} & =1+\frac{1}{2} \varphi_{0}^{2}=\frac{u_{W}}{\Delta}+1, \\
\varphi_{0} & =\left(2 \frac{u_{W}}{\Delta}\right)^{\frac{1}{2}} .
\end{aligned}
$$

From the fact that (6) goes into (7) with small displacements, it follows that expression (7) is more accurate. And the decomposition of the secant with the same number of members is less accurate than the decomposition of the cosine. This is confirmed by a numerical estimate of the accuracy of determining the contact angle using formulas (5), (6), and (7). Comparison results for different $u_{0} / \Delta$ are presented in tab. 1 .

\section{Comparison of the results of calculating the angle for different formulas}

Table 1

\begin{tabular}{|c|c|c|c|c|c|}
\hline $\begin{array}{c}u_{0} / \Delta \\
\text { Formulas }\end{array}$ & 0,1 & 0,5 & 1,0 & 1,5 & 2,0 \\
\hline$(5)$ & 24,62 & 48,19 & 60 & 66,42 & 70,53 \\
\hline$(6)$ & 24,43 & 46,78 & 57,3 & 62,76 & 66,16 \\
\hline$(7)$ & 25,62 & 57,3 & 81,03 & 99,24 & 114,6 \\
\hline
\end{tabular}

From the numerical comparison it follows that the calculations by the formula (7) obtained by the decomposition of the secant are close to the calculations by the original formula (5) only at angles not exceeding $20^{\circ}$.

From formula (7), the dependence for wear on the contact angle in a bearing will look like:

$$
u_{W}=\Delta \frac{\varphi_{0}^{2}}{2}
$$

The resulting expression (8) is differentiated along the path of friction and together with expression (3) we substitute into (1). As a result, we get:

$$
\Delta \varphi_{0}(S) \frac{d \varphi_{0}}{d S}=K_{W} f\left(\frac{3 Q}{4 b R_{1} \varphi_{0}(S) E}\right)^{m}\left(\frac{V \Delta}{a}\right)^{n} .
$$

Or:

$$
\Delta \varphi_{0}{ }^{m+1} d \varphi_{0}=K_{W} f\left(\frac{3 Q}{4 b R_{1} E}\right)^{m}\left(\frac{V \Delta}{a}\right)^{n} d S .
$$
obtain:

This is an ordinary differential equation with separable variables. After integrating equation (10), we 


$$
\frac{\varphi_{0}{ }^{m+2}}{m+2}=\frac{K_{W} f}{\Delta}\left(\frac{3 Q}{4 b R_{1} E}\right)^{m}\left(\frac{V \Delta}{a}\right)^{n} S+C \text {. }
$$

If we assume that in the initial period of time $S=0$ the contact angle is zero $\varphi_{0}=0$, then the integration constant $C=0$.

Thus, the dependence for the contact angle will take the form:

$$
\varphi_{0}=\left(\frac{(m+2) K_{W} f}{\Delta}\left(\frac{3 Q}{4 b R_{1} E}\right)^{m}\left(\frac{V \Delta}{a}\right)^{n} S\right)^{\frac{1}{m+2}} .
$$

Finally, taking into account expression (8), the calculation formula for maximum wear in a sliding bearing, depending on the friction path, will take the form:

$$
u_{W}=\frac{\Delta}{2}\left((m+2) K_{W} f \Delta^{n-1}\left(\frac{3 Q}{4 b R_{1} E}\right)^{m}\left(\frac{V}{a}\right)^{n} S\right)^{\frac{2}{m+2}} .
$$

The obtained dependence for the calculation of wear allows you to analyze the effect on wear of structural and operational parameters of bearings. This makes it possible to choose the optimal parameters of the bearings at the stage of design preparation of the machine according to the criterion of maximum wear resistance.

\section{Example of calculating the wear of a sliding bearing.}

We take the following initial data:

1. Clearance in bearing $\Delta=0.05 \mathrm{~mm}$;

2. Wear resistance parameters: $K_{W}=1.76 \cdot 10^{10} ; m=1.58 ; n=1.14$;

3. Coefficient of friction $f=0.05$;

4. Normal bearing load: $Q=100 \ldots 500 \mathrm{~N}$;

5. Bearing working width $b=15 \mathrm{~mm}$, bearing radius $R_{1}=25 \mathrm{~mm}$;

6. The modulus of elasticity of bronze $E=1.15 \cdot 10^{5} \mathrm{MPa}$;

7. Sliding speed in bearing $V_{1}=1 \mathrm{~m} / \mathrm{s}, V_{2}=3 \mathrm{~m} / \mathrm{c}$;

8. Coefficient of thermal diffusivity of bronze $a=110 \mathrm{~m}^{2} / \mathrm{s}$;

9. Bearing life $T=100 \mathrm{~h}\left(S=10^{8} \mathrm{~mm}\right)$.

The results of the calculation of wear as a function of loading and sliding speed are shown in Fig. 2.

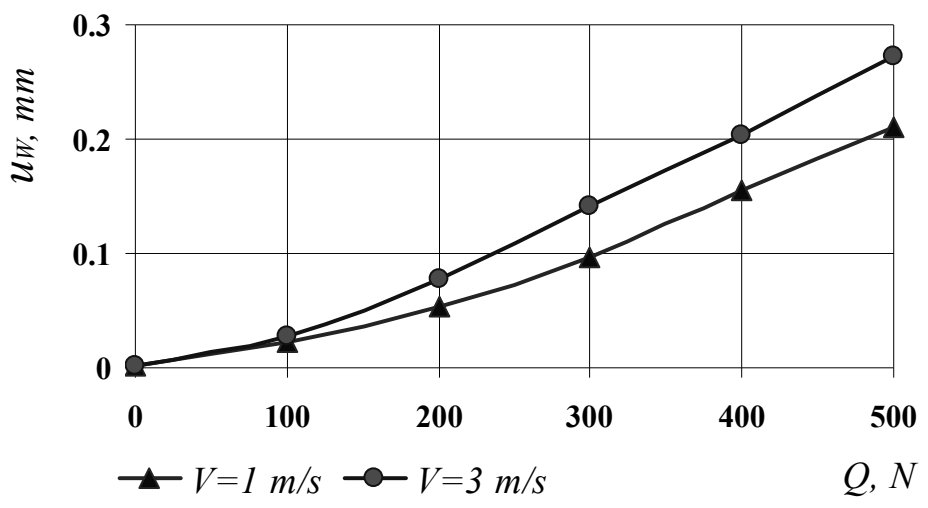

Fig. 1 - The wear as a function of loading and sliding speed in sliding bearing 


\section{To determine the parameters of the law of wear}

In the process of solving the direct wear-contact problem, the parameters of the law of wear were taken known as the initial data. However, the determination of wear parameters is also a rather complicated problem. This is due to the need for experimental wear tests. Moreover, the test conditions should be close to the actual operating conditions of the friction unit. In addition, the results of direct wear tests allow us to determine the dependence of wear on the time or friction path, and not on the parameters of the law of wear. This requires the solution of reverse wear-contact problems.

Let us briefly consider the method of determining the parameters of the law of wear as applied to a sliding bearing in the form (1).

Let, according to test results, the approximation of the dependence of the contact arc upon bearing wear on the friction path in the form:

$$
\varphi_{0}=c S^{\beta}
$$

where $c, \beta$ is the parameters of power approximation of the experimental wear curve.

We integrate the law of wear (1) along the path of friction and substitute the expression for wear (8) in the left side, and the expression for maximum contact pressures (3) in the right side:

$$
\Delta \frac{\varphi_{0}^{2}}{2}=K_{W} f \int_{0}^{S}\left(\frac{3 Q}{4 b R_{1} \varphi_{0}(S) E}\right)^{m}\left(\frac{V \Delta}{a}\right)^{n} d S
$$

After substituting the approximation (14) and integration, we obtain:

$$
\Delta \frac{c^{2} S^{2 \beta}}{2}=K_{W} f\left(\frac{3 Q}{4 b R_{1} c E}\right)^{m}\left(\frac{V \Delta}{a}\right)^{n} \frac{S^{1-\beta m}}{1-\beta m}
$$

From the condition of satisfiability of equation (16) we obtain:

$$
2 \beta=1-2 \beta m
$$

From:

$$
m=\frac{1-2 \beta}{\beta}
$$

We introduce the notation: $\frac{3 Q}{4 b R_{1} E}=P$. Then, after substitutions and transformations, equation takes the form:

$$
c^{2} \beta=\frac{K_{W} f}{\Delta}\left(\frac{P}{c}\right)^{m}\left(\frac{V \Delta}{a}\right)^{n} .
$$

To determine the second parameter, tests are performed at two values of the slip velocity. As a result, we obtain two approximating functions of the form (14). After substituting the parameters of these functions into equation (19), we obtain the system of equations:

$$
\left.\begin{array}{l}
c_{1}^{2} \beta=\frac{K_{W} f}{\Delta}\left(\frac{P}{c_{1}}\right)^{m}\left(\frac{V_{1} \Delta}{a}\right)^{n} ; \\
c_{2}^{2} \beta=\frac{K_{W} f}{\Delta}\left(\frac{P}{c_{2}}\right)^{m}\left(\frac{V_{2} \Delta}{a}\right)^{n} \cdot
\end{array}\right\}
$$

Dividing one equation by another, we find an expression for the parameter of the law of wear $n$ : 


$$
n=(m+2) \frac{\lg \left(c_{1} / c_{2}\right)}{\lg \left(V_{1} / V_{2}\right)} .
$$

To determine the coefficient $K_{W}$ use one of equations (20):

$$
K_{W}=\frac{c^{2} \beta \Delta}{f}\left(\frac{c_{1}}{P}\right)^{m}\left(\frac{a}{V_{1} \Delta}\right)^{n} .
$$

Thus, for the correct use of the formula for the calculation of wear (13), the parameters of the law of wear should be obtained by the above method. The solution of direct and inverse wear-contact problems in conjunction with laboratory tests allows to obtain adequate design models of wear.

We also write the solution of the direct problem for a sliding bearing, if the law of wear is adopted in the classical form:

$$
\frac{d u_{W}}{d S}=K_{W} \sigma^{m}\left(\varphi_{0}\right)
$$

It is for this form of the law of wear that wear resistance parameters are given in reference books.

After substitution of the equilibrium equation (3) and the geometrical condition (8) into this wear law, after transformations, we obtain:

$$
u_{W}=\frac{\Delta}{2}\left(\frac{(m+2) K_{W}}{\Delta}\left(\frac{3 Q}{4 b R_{1}}\right)^{m} S\right)^{\frac{2}{m+2}}
$$

The resulting formula contains only the parameters of the law of wear and the source data for the calculation of the bearing.

\section{Conclusion}

It is shown that the calculated estimate of wear of friction units is difficult due to the complexity of the interaction processes of the elements of the tribosystem. Nonlinearity of wear processes leads to mathematical difficulties in the construction of wear models. The paper proposes an approximate method for solving a direct wear-contact problem for a sliding bearing. The calculation was carried out for maximum contact pressures at the center of the wear area. Trigonometric functions in the solution process were replaced by approximate power series expansions. An example is given of the numerical implementation of the obtained closed formula for calculating the wear of a sliding bearing.

\section{References}

1. Chernets, M. V. (2015). Prediction of the life of a sliding bearing based on a cumulative wear model taking into account the lobing of the shaft contour. Journal of Friction and Wear, 36(2), 163-169. doi: $10.3103 / \mathrm{S} 1068366615020038$

2. Soldatenkov, I.A. (2010). Evolution of contact pressure during wear of the coating in a thrust sliding bearing. Journal of Friction and Wear, 31(2), 102-106. doi:10.3103/S1068366610020029

3. Goryacheva, I.G. \& Mezrin, A.M. Simulation of combined wearing of the shaft and bush in a heavily loaded sliding bearing J. Frict. Wear (2011) 32: 1. doi:10.3103/S1068366611010053

4. Soldatenkov I. A., Mezrin A. M., Sachek B. Ya. Implementation of asymptotics of the wear contact problem solution for identifying the wear law based on the results of tribological tests, Journal of Friction and Wear, 2017, 38(3), pp. 173-177.

5. Mezrin, A.M. (2009). Determining local wear equation based on friction and wear testing using a pinon-disk scheme. Journal of Friction and Wear, 30(4), 242-245. doi:10.3103/S1068366609040035

6. Bulgarevich, S.B., Boiko, M.V., Lebedinskii, K.S., Marchenko D.Yu. (2014). Kinetics of sample wear on four-ball friction-testing machine using lubricants of different consistencies. Journal of Friction and Wear, 35(6), 531-537. doi:10.3103/S106836661406004X 
Direct wear-contact task for radial sliding bearing

7. Rezaei, A., Paepegem, W.V., Baets, P.D., Ost, W., Degrieck, J. (2012). Adaptive finite element simulation of wear evolution in radial sliding bearings. Wear, 296(1-2), 660-671. https://doi.org/10.1016/j.wear.2012.08.013

8. Dykha, A.V., Kuzmenko, A.G. (2015). Solution to the problem of contact wear for four-ball weartesting scheme. Journal of Friction and Wear, 36(2), 138-143. doi: 10.3103/S1068366615020051

9. Dykha, A., Sorokatyi, R., Makovkin, O., Babak, O. Calculation-experimental modeling of wear of cylindrical sliding bearings. Eastern-European Journal of Enterprise Technologies, 2017, 5/1 (89), 51-59. doi: 10.15587/1729-4061.2017.109638

10. Dykha A., Marchenko D. Prediction the wear of sliding bearings. International Journal of Engineering \& Technology, 2018, 7 (2.23), pp. 4-8. doi: 10.14419/ijet.v7i2.23.11872

Дыха А.В., Бабак О.П., Дытынюк В.А. Прямая износоконтактная задача для радиального подшипника скольжения.

Показано, что расчетная оценка износа узлов трения затруднена вследствие сложности процессов взаимодействия элементов трибосистемы. Нелинейность процессов изнашивания приводит к математическим трудностям при построении моделей износа. В работе предложен приближенный метод решения прямой износо-контактной задачи для подшипника скольжения. Расчет проводился для максимальных контактных давлений в центре площадки изнашивания. Тригонометрические функции в процессе решения заменялись приближенными разложениями в степенные ряды. Приведен пример численной реализации полученной замкнутой формулы для расчета износа подшипника скольжения.

Ключевые слова: контактные давления, скорость скольжения, износоконтактная задача, приближенный подход.

\section{"Problems of Tribology" E-mail: tribosenator@gmail.com}

